\title{
Transient mitochondrial permeability transition pore opening after neonatal cardioplegic arrest
}

\author{
Chung Ho Leung, BSc, Lixing Wang, MD, PhD, Yaqin Yana Fu, MD, William Yuen, and \\ Christopher A. Caldarone, MD
}

\begin{abstract}
Background: Neonatal cardioplegic arrest is associated with apoptosis-related mitochondrial dysfunction, including Bax translocation to the mitochondria, mitochondrial permeabilization, cytochrome c release, and electron transport chain dysfunction. We sought to characterize the time course and mode of postcardioplegic mitochondrial membrane permeabilization and hypothesize that permeabilization is transient and mediated by the mitochondrial permeability transition pore.
\end{abstract}

Methods: Isolated, perfused neonatal rabbit hearts underwent 60 minutes of warm crystalloid cardioplegic arrest followed by 120 minutes of reperfusion. Mitochondrial permeabilization was evaluated by means of infusion of 2-deoxy $\left[{ }^{3} \mathrm{H}\right]$ glucose and subsequent detection of entrapment in isolated mitochondrial fractions. Groups included preloading with 2-deoxy $\left[{ }^{3} \mathrm{H}\right]$ glucose followed by cardioplegia and reperfusion (CCP), cardioplegia and cyclosporin A (specific inhibitor of mitochondrial permeability transition pore opening; CCP $+\mathrm{CsA}$ ) or HA14-1 (Bcl-2 inhibitor; CCP + HA), and noncardioplegia control hearts (non-CCP). Reconstitution of mitochondrial integrity was tested by means of delayed infusion of 2-deoxy $\left[{ }^{3} \mathrm{H}\right]$ glucose 30 minutes after reperfusion (P-CCP).

\begin{abstract}
Results: Cardioplegic arrest was associated with mitochondrial permeability transition pore opening, Bax translocation, cytochrome c release, radical oxygen species production, and electron transport chain dysfunction. Inhibition of mitochondrial permeability transition pore opening by cyclosporin A ameliorated this response, whereas inhibition of Bcl-2 exacerbated these changes. Postreperfusion entrapment of 2-deoxy $\left[{ }^{3} \mathrm{H}\right]$ glucose was significantly reduced in comparison with that seen in CCP hearts, suggesting that closure of the mitochondrial permeability transition pore ensues within 30 minutes after reperfusion.
\end{abstract}

Conclusions: Apoptosis-related mitochondrial dysfunction in postcardioplegic neonatal hearts is mediated by mitochondrial permeability transition pore opening, which is transient and associated with deficits in electron transport. Clinical strategies directed to minimize mitochondrial permeability transition pore opening are likely to improve postoperative myocardial dysfunction after neonatal cardiac surgery. (J Thorac Cardiovasc Surg 2011;141:975-82)

As a critical mediator in apoptosis signaling pathways, mitochondria integrate upstream death stimuli and undergo structural and functional remodeling, with subsequent transmission of apoptotic signals to downstream executioner proteins. ${ }^{1}$ After protected ischemia (cardioplegic arrest) and reperfusion, we previously reported a constellation of apoptosis-related alterations, including Bax translocation, mitochondrial outer membrane permeabilization, cytochrome $\mathrm{c}$ release, and deficits in electron transport in the postoperative myocardium. ${ }^{2}$ These alterations, collectively termed apoptosis-related mitochondrial dysfunction,

\footnotetext{
From the Division of Cardiovascular Surgery, Hospital for Sick Children, Labatt Family Heart Center, Toronto, Ontario, Canada.

Disclosures: Authors have nothing to disclose with regard to commercial support.

Received for publication March 30, 2010; revisions received July 13, 2010; accepted

for publication Aug 9, 2010; available ahead of print Sept 30, 2010.

Address for reprints: Christopher A. Caldarone, MD, Division of Cardiovascular Sur-

gery, the Hospital for Sick Children, 555 University Ave, Toronto, Ontario, Canada,

M5G 1X8 (E-mail: christopher.caldarone@sickkids.ca).

$0022-5223 / \$ 36.00$

Copyright (c) 2011 by The American Association for Thoracic Surgery

doi:10.1016/j.jtcvs.2010.08.030
}

are detectable within hours of cardioplegic arrest and are associated with deficits in global myocardial performance in laboratory models ${ }^{2,3}$ and might contribute to the postoperative myocardial dysfunction observed in neonatal patients after cardiac surgery. ${ }^{4}$ Because of the close interplay between mitochondrial structure and energy production, ${ }^{5}$ preservation of mitochondrial architectural and functional integrity is an important cardioprotective strategy in the postoperative neonatal heart. ${ }^{3}$

The mitochondrial permeability transition pore (MPTP) is a nonspecific pore spanning the inner and outer mitochondrial membrane, and its opening during reperfusion results in impairment of mitochondrial integrity and, under some circumstances, cell death. ${ }^{6}$ Depending on the extent of ischemia-reperfusion injury, MPTP opening is subclassified into transient opening or irreversible, long-lasting opening, and the duration of MPTP opening is a mediator of cell fate (apoptosis vs necrosis), ${ }^{7}$ which corresponds to cardiac performance (reversible vs irreversible cardiac functional recovery). We have previously demonstrated that selective inhibition of MPTP opening after cardioplegic arrest leads 


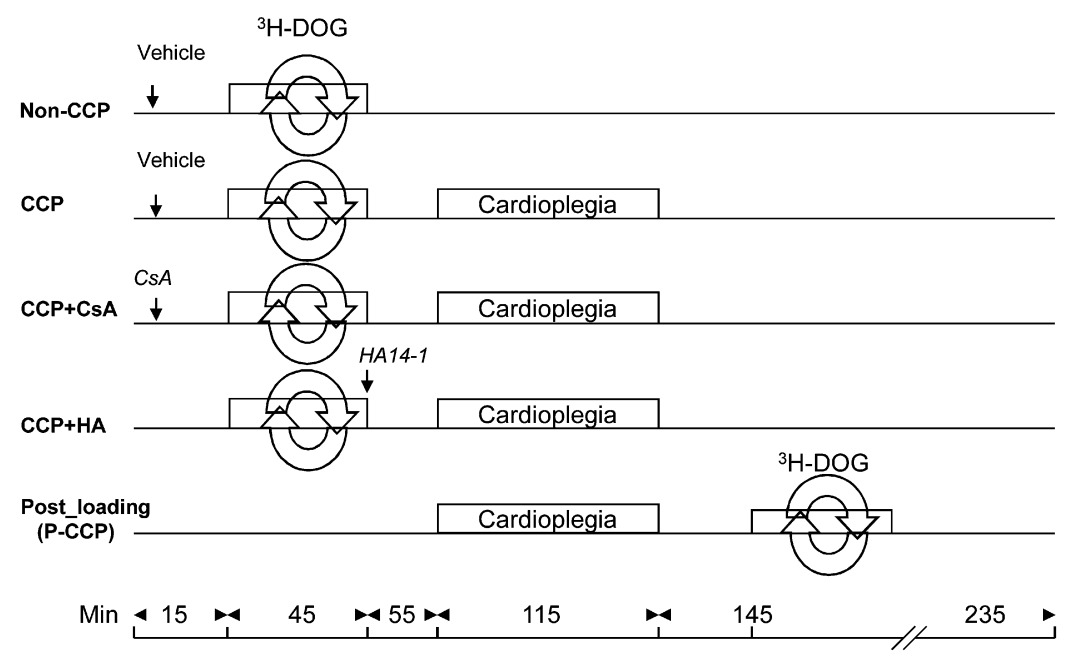

FIGURE 1. Experimental design showing time course of perfusion of isolated hearts in the noncardioplegia control (non-CCP), preloading with 2-deoxy $\left[{ }^{3} \mathrm{H}\right]$ glucose followed by cardioplegia and reperfusion $(C C P)$, cardioplegia and cyclosporin A $(C C P+C s A)$, cardioplegia and $\mathrm{HA} 14-1(C C P+H A)$, and delayed infusion of 2-deoxy $\left[{ }^{3} \mathrm{H}\right]$ glucose 30 minutes after reperfusion $(P-C C P)$ groups. ${ }^{3} H$-DOG, 2-Deoxy $\left({ }^{3} \mathrm{H}\right)$ glucose.

supernatant from the second spin after the pellet was resuspended. The pooled supernatant was centrifuged at $3000 \mathrm{~g}$ to sediment SSM, which was washed twice and resuspended in $\mathrm{KME}$ buffer $(100 \mathrm{mmol} / \mathrm{L} \mathrm{KCl}, 50$ $\mathrm{mmol} / \mathrm{L}$ MOPS, and $0.5 \mathrm{mmol} / \mathrm{L}$ EGTA).

\section{Mitochondrial Permeabilization and Cytochrome c Content}

The integrity of the mitochondrial outer membrane was assessed by measuring the boost of oxygen consumption of mitochondrial complex IV after administration of exogenous cytochrome $\mathrm{c}$ into the respiratory chamber. The subsequent increase in complex IV activity reflects the permeabilization of the outer mitochondrial membrane. ${ }^{16}$

Mitochondrial cytochrome c content was determined by using the Agilent 8453 UV-visible Spectrophotometer (Agilent Technologies, Waldbronn, Germany) with dual-cuvette methods, as described by William. ${ }^{17}$ Each cuvette contained $0.5 \mathrm{mg}$ of mitochondria solubilized in 5\% deoxycholate in $10 \mathrm{mmol} / \mathrm{L}$ sodium phosphate ( $\mathrm{pH}$ 7.0). The oxidized cuvette contained $5 \mathrm{mmol} / \mathrm{L}$ potassium ferricynaide, and the reduced cuvette contained $5 \mathrm{mmol} / \mathrm{L}$ ascorbate, to which several grains of sodium dithionate were added. The cytochrome c content was determined by the difference of oxidized and reduced spectra and standardized by means of mitochondrial citrate synthase (CS) activity.

\section{Mitochondrial Oxygen Consumption Measurement}

Isolated mitochondrial oxygen consumption was measured in buffer containing $100 \mathrm{mmol} / \mathrm{L} \mathrm{KCl}, 50 \mathrm{mmol} / \mathrm{L}$ MOPS, $1.0 \mathrm{mmol} / \mathrm{L} \mathrm{EGTA}$, $5.0 \mathrm{mmol} / \mathrm{L} \mathrm{KH}_{2} \mathrm{PO}_{4}$, and $5 \%$ defatted bovine serum albumin at $30^{\circ} \mathrm{C}$ by using a Clark-type electrode (Instech Laboratories, Inc, Plymouth, $\mathrm{Pa})$. As shown in Figure 2, mitochondrial respiratory state 2 and state 3 for complexes I, II, and IV were measured in the presence of sequential administration of substrates and inhibitors (glutamate and malate for complex I, rotenone and succinate for complex II, and antimycin, $\mathrm{N}, \mathrm{N}, \mathrm{N}^{\prime}, \mathrm{N}^{\prime}-$ tetramethyl- $p$-phenylenediamine, and ascorbate for complex IV) added in the following order and final concentrations: $2.5 \mathrm{mmol} / \mathrm{L}$ glutamate and $2.5 \mathrm{mmol} / \mathrm{L}$ malate, $1 \mathrm{mmol} / \mathrm{L}$ lower dose of adenosine diphosphate, $2 \mathrm{mmol} / \mathrm{L}$ higher dose of adenosine diphosphate, $2 \mu \mathrm{mol} / \mathrm{L}$ rotenone, 5 $\mathrm{mmol} / \mathrm{L}$ succinate, $1 \mu \mathrm{mol} / \mathrm{L}$ antimycin $\mathrm{A}, 1 \mathrm{mmol} / \mathrm{L}$ ascorbate, and $0.4 \mathrm{mmol} / \mathrm{L} \mathrm{N}, \mathrm{N}, \mathrm{N}^{\prime}, \mathrm{N}^{\prime}$-tetramethyl-p-phenylenediamine). Mitochondrial respiratory activity was expressed as the amount of oxygen (nanomoles) consumed per minute per milligram of mitochondrial protein. Mitochondrial complexes I, II, and IV respiratory control ratios were expressed as follows: state 3/state 2 . The voltage signal was amplified and digitized by using PowerLab/4sp (AD Instruments, Inc, Colorado Springs, Colo). All the substrates and inhibitors were purchased from Sigma-Aldrich (St Louis, Mo).

\section{In Situ Measurement of MPTP Opening}

As described previously, ${ }^{18}$ hearts were homogenized, and samples of crude ventricular homogenate and mitochondria were assayed for tritium $\left(\left[{ }^{3} \mathrm{H}\right]\right)$. The CS activity of mitochondrial fraction was measured. Mitochondrial entrapment of $\left[{ }^{3} \mathrm{H}\right]$ DOG 6-phosphate was expressed as $10^{5} \times$ (Mitochondrial $\left[{ }^{3} \mathrm{H}\right] \mathrm{dpm}$ per unit of $\left.\mathrm{CS}\right) /\left(\right.$ Total heart $\left[{ }^{3} \mathrm{H}\right] \mathrm{dpm}$ [g wet weight]). In this calculation CS activity is used to correct for variations in the recovery of intact mitochondria, and the total homogenate $\left[{ }^{3} \mathrm{H}\right]$ takes into account differences in loading of hearts with $\left[{ }^{3} \mathrm{H}\right]$ DOG 6-phosphate between experiments.

\section{CS Activity Assay}

SSM $(100 \mu \mathrm{g})$ was dissolved in $5 \%$ cholate and diluted to $100 \mu \mathrm{L}$ with KME buffer to make the SSM mixture. The CS activity measurement was performed in a $1-\mathrm{mL}$ reaction buffer containing $1 \mu \mathrm{g}$ of SSM mixture, $0.1 \mathrm{mmol} / \mathrm{L} 5,5^{\prime}$-dithio-bis (2-nitrobenzoic acid), $0.4 \mathrm{mmol} / \mathrm{L}$ acetyl coenzyme $\mathrm{A}$, and $0.5 \mathrm{mmol} / \mathrm{L}$ oxaloacetic acid (OAA) at $37^{\circ} \mathrm{C}$. The increase of absorbance at $412 \mathrm{~nm}$ caused by the CS activity was recorded with an Agilent 8453 UV-visible Spectrophotometer (Agilent Technologies) every 5 seconds for 2 minutes before and after addition of OAA. The absorbance rate change per minute (Delta A-412 nm/min) was calculated by the subtraction of the Delta A-412 $\mathrm{nm} / \mathrm{min}$ after adding OAA from the Delta A- $412 \mathrm{~nm} / \mathrm{min}$ before adding OAA. One unit of CS activity was calculated by using the ratio of Delta $\mathrm{A}-412 \mathrm{~nm} \mathrm{~min}{ }^{-1}$ to extinction coefficient (13.6).

\section{Detection of Mitochondrial Reactive Oxygen Species Production}

The method for reactive oxygen species (ROS) measurement was described by Korge and associates. ${ }^{19}$ Briefly, malate/glutamate $(2.5 \mathrm{mmol} /$ L each)-energized SSM was incubated in mitochondrial respiratory buffer with $10 \mu \mathrm{mol} / \mathrm{L}$ CM- $\mathrm{H}_{2} \mathrm{DCF}$ diacetate (Molecular Probes, Eugene, Ore) at room temperature for 30 minutes. ROS production was monitored from 


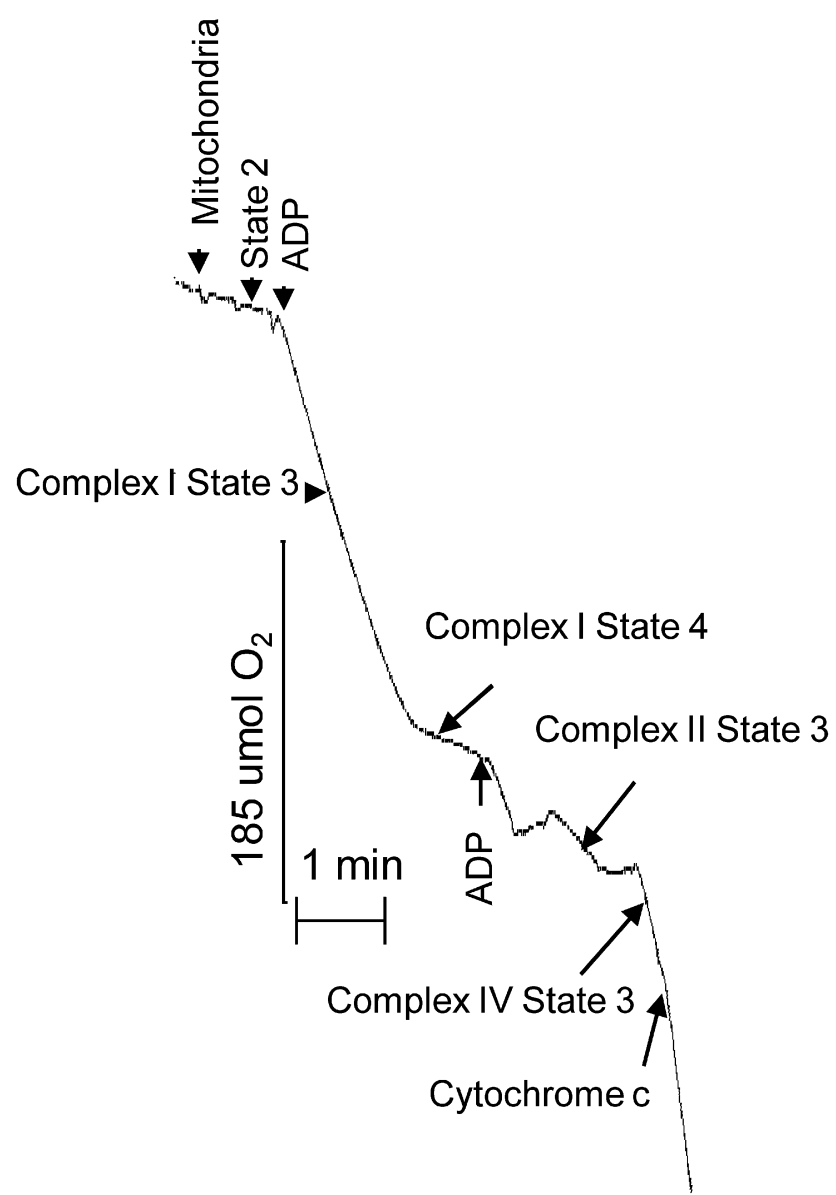

FIGURE 2. Representative trace of mitochondrial oxygen consumption in complexes I,II, and IV and before and after administration of exogenous cytochrome c. $A D P$, Adenosine diphosphate.

reduced dichlorofluorescin oxidation (excitation/emission, 490/525) with a microplate spectroflurometer (Spectra MAX Gemini EM; Molecular Devices, Sunnyvale, Calif).

\section{Mitochondrial Bax and Bcl-2 Content}

Mitochondrial Bax and Bcl-2 concentrations were examined by means of Western blotting of mitochondrial protein fractions. Briefly, proteins were electrophoresed in $10 \%$ sodium dodecylsulfate-polyacrylamide gels, transblotted to nitrocellulose membrane, and probed with antirabbit Bax (N-20, 1:1000 dilution; Santa Cruz Biotechnology, Santa Cruz, Calif) and anti-rabbit Bcl-2 (N-19, 1:1000 dilution, Santa Cruz Biotechnology). For protein-loading controls, the membranes were stripped and reprobed with anti-mouse cytochrome $c$ oxidase subunit IV (1:10,000 dilution, Molecular Probes). Secondary antibodies were coupled to horseradish peroxidase (anti-mouse IgG, 1:5000 dilution, and anti-rabbit IgG, 1:1000 dilution, Santa Cruz Biotechnology). The resulting autoradiographs were scanned and quantified. The amounts of mitochondrial Bax and Bcl-2 were normalized by cytochrome c oxidase subunit IV to control for variation in mitochondrial protein loading.

\section{Statistics}

Data are expressed as means \pm standard deviations. Planned comparisons between 2 groups were made with $t$ tests, as specified. Multiplegroup comparisons were made with analysis of variance with Tukey's test for post hoc comparisons, unless otherwise specified.

\section{RESULTS \\ Mitochondrial Permeabilization and Cytochrome c Retention}

Cardioplegic arrest and reperfusion were associated with a deficit of complex IV activity in $\mathrm{CCP}$ and $\mathrm{CCP}+\mathrm{HA}$ hearts when compared with that seen in non-CCP hearts $(2.13 \pm$ 0.19 and $1.91 \pm 0.25$ vs $2.88 \pm 0.22 \mu \mathrm{mol} \mathrm{O} \mathrm{O}_{2} \cdot \mathrm{min}^{-1}$. $\mathrm{mg}^{-1} ; P<.02$ and $P<.01$, respectively), and the complex IV deficit was minimized in CsA-treated hearts (Figure 3, A). After administration of exogenous cytochrome $\mathrm{c}$, the deficit of complex IV activity in $\mathrm{CCP}$ and $\mathrm{CCP}+\mathrm{HA}$ hearts was reversed, and no significant differences in complex IV activity were found among the non-CCP, $\mathrm{CCP}, \mathrm{CCP}+\mathrm{CsA}$, and $\mathrm{CCP}+\mathrm{HA}$ groups, indicating that cardioplegic arrest is associated with mitochondrial permeabilization and cytochrome c-dependent reversible deficits in complex IV activity ( $P>.79$ for all comparisons).

Complex IV activity with and without administration of exogenous cytochrome c can be compared as a ratio and used to assess the extent of mitochondrial permeabilization. If the ratio is 1 , then exogenous cytochrome $\mathrm{c}$ has no effect, and there is no evidence of outer mitochondrial membrane permeabilization. Ratios greater than 1 suggest that exogenous cytochrome $\mathrm{c}$ boosts electron transport, and the magnitude of the boost correlates with outer mitochondrial membrane permeabilization. ${ }^{16}$ The cytochrome $\mathrm{c}$ boost was greater in CCP and CCP + HA hearts than in non$\mathrm{CCP}$ and CCP $+\mathrm{CsA}$ hearts $(1.81 \pm 0.317$ and $1.85 \pm$ 0.297 vs $1.123 \pm 0.078$ and $1.269 \pm 0.071$, respectively; $P<.01$ all comparisons). There was no significant difference between CsA and Non-CCP mitochondria $(P=.68$; Figure 3, $B$ ).

After cardioplegic arrest, cytochrome c was released from the intermembrane space into the cytosol, and the mitochondrial content of cytochrome $\mathrm{c}$ was reduced. In comparison with non-CCP mitochondria, cytochrome $\mathrm{c}$ content in $\mathrm{CCP}$ and $\mathrm{CCP}+\mathrm{HA}$ mitochondria was lower $(108.2 \pm 8.1$ and $100.8 \pm 7.0$ vs $161 \pm 11.1 \mathrm{pmol} \cdot \mathrm{CS}$ unit $^{-1} \cdot \mathrm{mg}^{-1}$ protein; $P<.01$ respectively; Figure $3, C$ ), and CsA-treated mitochondria had better preservation of cytochrome $\mathrm{c}$ than CCP mitochondria $(136.7 \pm 15.7$ vs $108.2 \pm 8.1 \mathrm{pmol} \cdot \mathrm{CS}$ unit ${ }^{-1} \cdot \mathrm{mg}^{-1}$ protein, $\left.P<.01\right)$.

\section{In Situ Measurement of MPTP Opening}

Cardioplegic arrest and reperfusion resulted in increased MPTP opening, which was evident in the higher entrapment of $\left[{ }^{3} \mathrm{H}\right]$ DOG in CCP hearts compared with that seen in nonCCP hearts $\left(67.12 \pm 11.59\right.$ vs $22.88 \pm 8.63 \mathrm{dpm} \cdot \mathrm{CS}$ unit $^{-1}$ $\cdot \mathrm{g}^{-1}$ wet weight, $P<.03$, Figure 4$)$. Mitochondrial $\left[{ }^{3} \mathrm{H}\right]$ DOG entrapment was diminished in $\mathrm{CCP}+\mathrm{CsA}$ hearts compared with that seen in CCP hearts $(36.77 \pm 7.71$ vs $67.12 \pm$ $11.59 \mathrm{dpm} \cdot \mathrm{CS}$ unit $^{-1} \cdot \mathrm{g}^{-1}$ wet weight, $P=0.03$ by using Fisher's least significant difference test and $P=.18$ by 

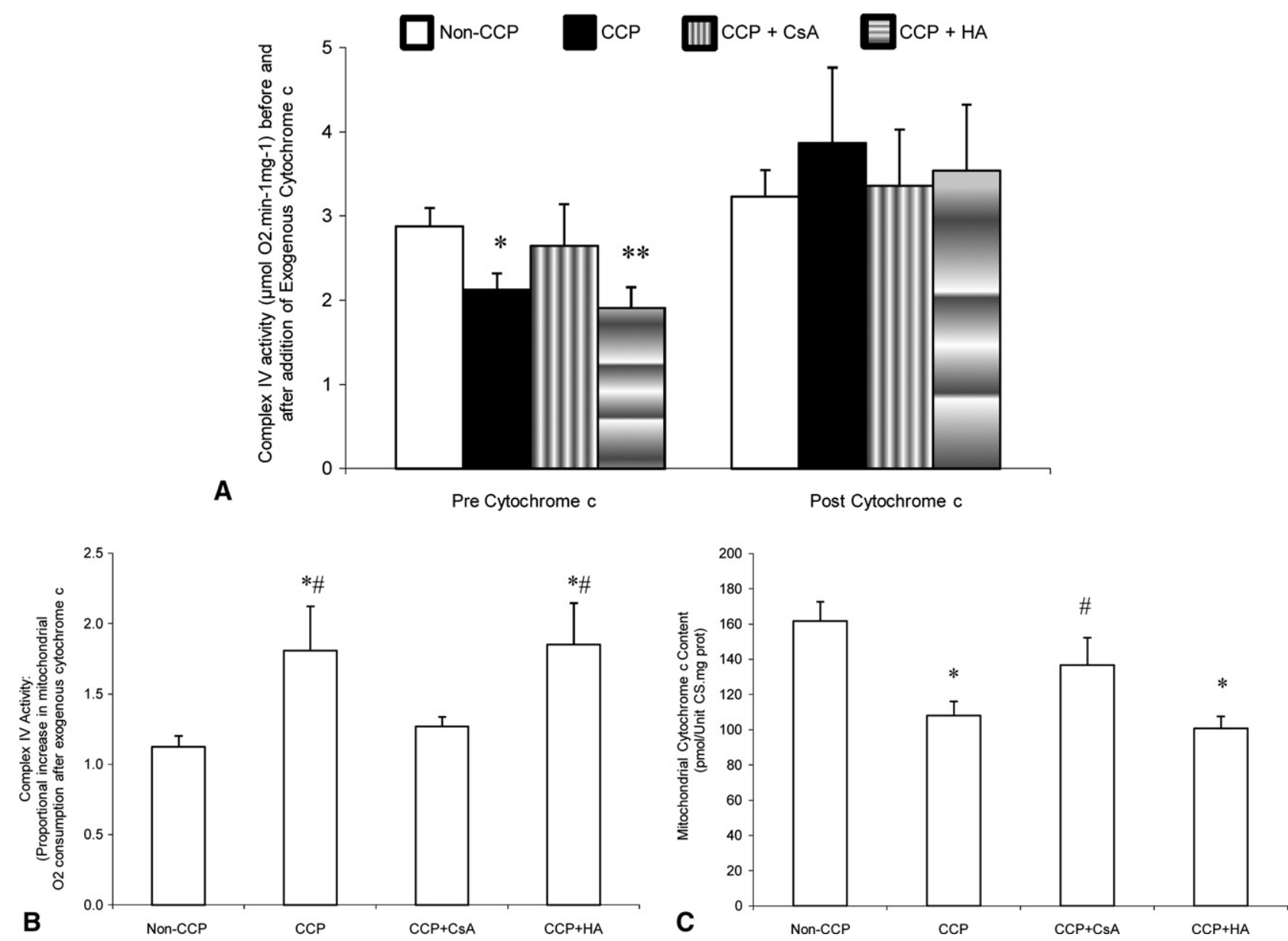

FIGURE 3. A, Mitochondrial complex IV activity before the addition of exogenous cytochrome $\mathrm{c}$ to isolated mitochondria. $* P<.02$ and $* * P<.01$ versus the non-CCP group. B, Fold increase of complex IV activity after addition of exogenous cytochrome $\mathrm{c}$. $* P<.01$ versus the non-CCP group and $\# P<.01$ versus the $\mathrm{CCP}+\mathrm{CsA}$ group. $\mathrm{C}$, Mitochondrial cytochrome $\mathrm{c}$ retention. ${ }^{*} P<.01$ versus the non-CCP group and \#P<.01 versus the CCP group. For definitions of the study groups, see the legend for Figure 1.

using Tukey's test) and enhanced in HA14-1-treated hearts compared with CCP hearts $(105.12 \pm 47.83$ vs $67.12 \pm$ $11.59 \mathrm{dpm} \cdot \mathrm{CS}$ unit $^{-1} \cdot \mathrm{g}^{-1}$ wet weight, $P=.06$ ).

To test whether the MPTP opening in CCP hearts is transient or long lasting, $\left[{ }^{3} \mathrm{H}\right]$ DOG was loaded after hearts had been reperfused for 30 minutes, as previously described by Javadov and coworkers. ${ }^{18}\left[{ }^{3} \mathrm{H}\right]$ DOG entrapment in the PCCP hearts was significantly reduced compared with $\left[{ }^{3} \mathrm{H}\right]$ DOG entrapment in the CCP hearts $(36.77 \pm 7.71 \mathrm{vs}$ $67.12 \pm 11.59 \mathrm{dpm} \cdot \mathrm{CS}$ unit $^{-1} \cdot \mathrm{g}^{-1}$ wet weight, $P<.05)$. The $\left[{ }^{3} \mathrm{H}\right]$ DOG entrapment data indicated that cardioplegic arrest and reperfusion induced MPTP opening, which was a transient event, and restoration of mitochondrial integrity was nearly complete after 30 minutes of reperfusion.

\section{Mitochondrial Oxygen Consumption}

The deficit in state 3 respiration for complex I was greater in the mitochondria of CCP and $\mathrm{CCP}+\mathrm{HA}$ hearts compared with that seen in non-CCP hearts $(1439 \pm 446$ and $851 \pm$ 381 vs $1978 \pm 279 \mathrm{nmol} \mathrm{O} \mathrm{O}_{2} \cdot \mathrm{min}^{-1} \cdot \mathrm{mg}^{-1}$ protein; $P=.059$ and $P<.01$, respectively; Table 1$)$. The deficit in the state 3 respiration for complex IV was also present in the mitochondria of $\mathrm{CCP}$ and $\mathrm{CCP}+\mathrm{HA}$ hearts compared with that seen in non-CCP hearts $(2127 \pm 626$ and $1907 \pm$ 390 vs $2876 \pm 222 \mathrm{nmol} \mathrm{O}{ }_{2} \cdot \mathrm{min}^{-1} \cdot \mathrm{mg}^{-1}$ protein $P<.02$ and .01, respectively). Deficiency of state 3 respiration for complex II was only identified in $\mathrm{CCP}+\mathrm{HA}$ hearts $\left(456 \pm 166 \mathrm{nmol} \mathrm{O} 2 \cdot \mathrm{min}^{-1} \cdot \mathrm{mg}^{-1}\right.$ protein in $\mathrm{CCP}+\mathrm{HA}$ hearts vs $648 \pm 65 \mathrm{nmol} \mathrm{O}{ }_{2} \cdot \mathrm{min}^{-1} \cdot \mathrm{mg}^{-1}$ protein in non-CCP hearts, $P<.05$ ). These deficits were minimized in the CCP + CsA hearts, although the protective effect was greatest with complexes I and IV. Cardioplegic arrest and reperfusion decreased the complex I respiratory control ratio in the mitochondria of CCP hearts compared with that seen in non-CCP hearts $(6.13 \pm 2.45$ vs $12.36 \pm 2.07$, $P<.01$, Table 2), whereas the decrease in CCP hearts was significantly reversed in CCP + CsA hearts $(16.34 \pm 9.93$ 


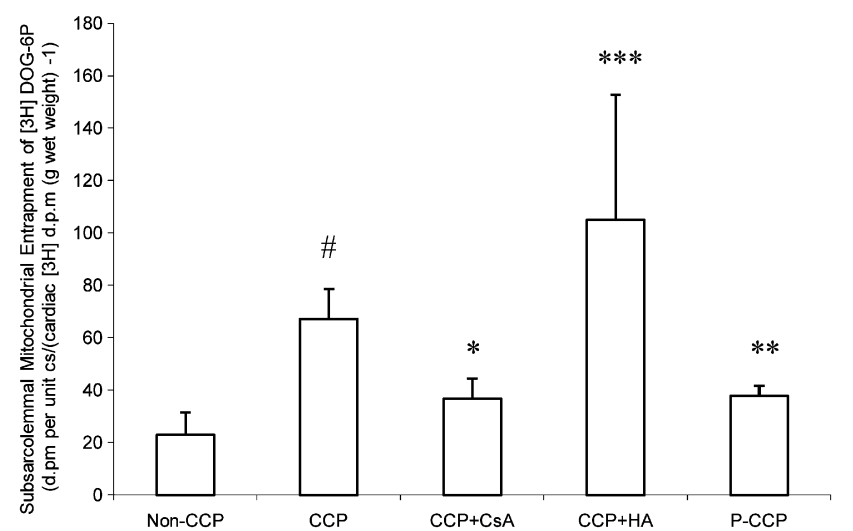

FIGURE 4. Subsarcolemmal mitochondrial entrapment of 2-deoxy $\left({ }^{3} \mathrm{H}\right)$ glucose $\left(\left[{ }^{3} H\right] D O G\right)$. $\# P<.03$ versus the non-CCP group and $* P=.03$, $* * P<.05$, and $* * * P=0.06$ versus the CCP group. For definitions of the study groups, see the legend for Figure 1.

vs $6.13 \pm 2.45, P<.05)$. The complex IV respiratory control ratio was also decreased in CCP hearts compared with that seen in non-CCP hearts $(9.19 \pm 2.22$ vs $18.34 \pm 4.21$, $P<.05)$, whereas the decrease was significantly reversed in CCP + CsA hearts compared with CCP hearts $(24.54 \pm$ 16.19 vs $9.19 \pm 2.22, P<.05)$.

\section{Mitochondrial ROS Production}

Cardioplegic arrest and reperfusion resulted in higher mitochondrial ROS production rates in $\mathrm{CCP}$ and $\mathrm{CCP}+\mathrm{HA}$ hearts compared with that seen in non-CCP hearts ( $48.2 \pm 21.4$ and $45.6 \pm 16.5$ vs $20.6 \pm 2.4 \mathrm{RFU} / \mathrm{mg}$ protein; $P<.05$ and $P=.06$, respectively), and ROS production was not different when comparing $\mathrm{CCP}+\mathrm{CsA}$ and non-CCP hearts $(23.8 \pm 1.6$ vs $20.6 \pm 2.4 \mathrm{RFU} / \mathrm{mg}$ protein; $P=.98$; Figure 5).

\section{Mitochondrial Bax and Bcl-2 Content}

Mitochondrial Bax concentrations were increased in the mitochondrial fraction in CCP hearts compared with those seen in non-CCP hearts $(1.06 \pm 0.33$ vs $0.42 \pm 0.22 \mathrm{AU}$, $P<.05)$, and $\mathrm{CCP}+\mathrm{CsA}$ hearts were not statistically different than non-CCP hearts $(P=.98)$. There was no difference in Bcl-2 content among these groups (Figure 6).

TABLE 1. Mitochondrial oxygen consumption (in nanomoles of oxygen per minute per milligram of protein)

\begin{tabular}{lccll}
\hline & & \multicolumn{3}{c}{ State 3 } \\
\cline { 3 - 5 } Groups & State 2 & Complex I & Complex II & Complex IV \\
\hline Non-CCP & $166 \pm 49$ & $1978 \pm 279$ & $648 \pm 65$ & $2876 \pm 222$ \\
$\mathrm{CCP}$ & $240 \pm 42$ & $1439 \pm 446 \S$ & $588 \pm 212$ & $2127 \pm 626 \dagger$ \\
$\mathrm{CCP}+\mathrm{CsA}$ & $156 \pm 99$ & $1816 \pm 228$ & $571 \pm 132$ & $2650 \pm 532$ \\
$\mathrm{CCP}+\mathrm{HA}$ & $209 \pm 23$ & $851 \pm 381^{*}$ & $456 \pm 166 \ddagger$ & $1907 \pm 390^{*}$ \\
\hline
\end{tabular}

Values are presented as means \pm standard deviations ( $\mathrm{n}=6$ for each group). For definitions of the study groups, see the legend for Figure $1 .{ }^{*} P<.01, \dagger P<.02, \uparrow P<.05$, and $\S P=.059$ versus the non-CCP group.
TABLE 2. Mitochondrial respiratory control ratio (state 3/state 2)

\begin{tabular}{lclc}
\hline \multicolumn{1}{c}{ Groups } & Complex I & Complex II & Complex IV \\
\hline Non-CCP & $12.36 \pm 2.07$ & $4.08 \pm 0.74$ & $18.34 \pm 4.21$ \\
CCP & $6.13 \pm 2.45^{*}$ & $2.50 \pm 0.45$ & $9.19 \pm 2.22 \dagger$ \\
CCP + CsA & $16.33 \pm 9.93 \ddagger$ & $5.15 \pm 3.25 \S$ & $24.54 \pm 16.19 \ddagger$ \\
CCP + HA & $4.09 \pm 1.93$ & $2.17 \pm 0.74 \ddagger$ & $9.24 \pm 1.70$ \\
\hline
\end{tabular}

Values are presented as means \pm standard deviations ( $\mathrm{n}=6$ for each group). For definitions of the study groups, see the legend for Figure $1 . * P<.01$ and $\dagger P<.05$

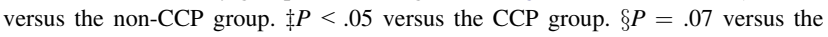
$\mathrm{CCP}+\mathrm{HA}$ group.

\section{DISCUSSION}

A putative target for cardioprotection during reperfusion is the MPTP. ${ }^{6}$ The MPTP remains closed throughout ischemia but opens at the time of reperfusion, ${ }^{20}$ and the opening of this channel is mediated by conditions such as intracellular oxidative stress, ROS production, and calcium overload. ${ }^{6}$ Sustained or irreversible opening of the MPTP leads to the dissipation of mitochondrial potential, cessation of oxidative phosphorylation, matrix swelling, and eventually outer membrane rupture. ${ }^{21}$ MPTP opening can be a reversible event and does not always lead to demonstrable mitochondrial swelling $^{22}$ and depolarization. ${ }^{23}$ Transient MPTP opening with full cardiac functional recovery is associated with mild forms of ischemia-reperfusion injury. ${ }^{7}$ Inhibition of MPTP opening prevents mitochondria-driven necrotic and apoptotic processes and apoptosis-related mitochondrial dysfunction in the postcardioplegic myocardium. ${ }^{3}$ The novel observations of the present study include the following: (1) transient MPTP opening occurred within 30 minutes of reperfusion after cardioplegic arrest, and MPTP resealing ensued within 30 minutes of reperfusion, and (2) precardioplegic arrest inhibition of MPTP opening by CsA prevented the occurrence of apoptosis-related mitochondrial dysfunction, whereas the facilitation of MPTP opening by the Bcl-2 inhibitor HA14-1 augmented the deficit of mitochondrial respiratory chain activity. These data suggest that MPTP opening plays an important role as a mediator of apoptosis-related mitochondrial

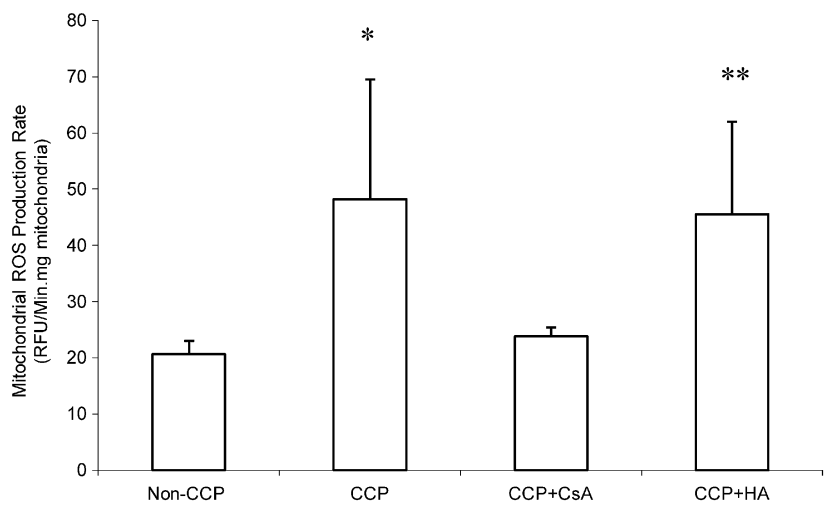

FIGURE 5. Isolated mitochondrial reactive oxygen species (ROS) production rate (RFU per minute per milligram of protein). $* P<.05$ and $* * P=.06$ versus the non-CCP group. For definitions of the study groups, see the legend for Figure 1. 

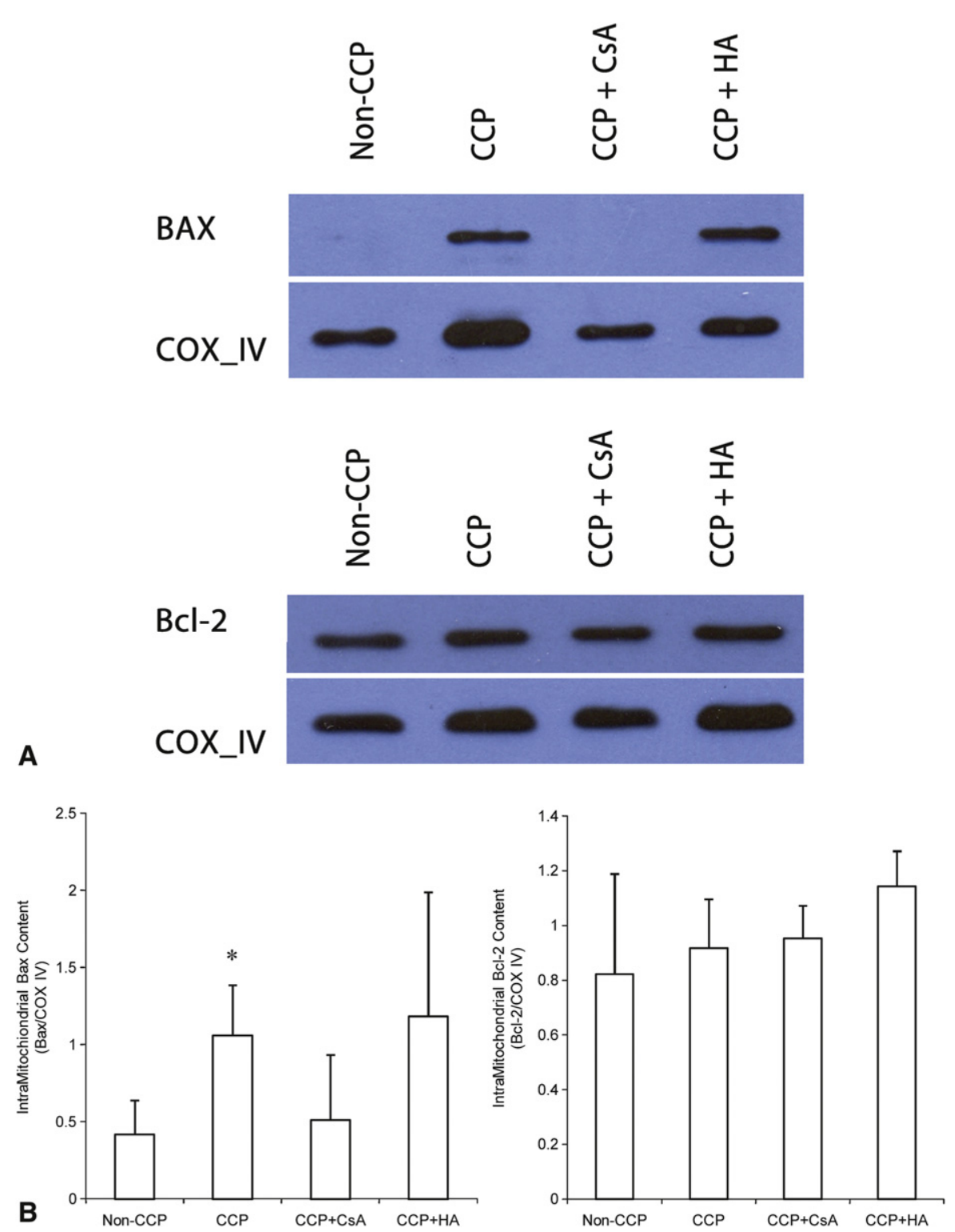

FIGURE 6. A, Representative immunoblots of mitochondrial Bax, Bcl-2, and cytochrome c oxidase IV (COX IV). *P<.05 versus the non-CCP group. B, Densitometric measurements of Bax and Bcl-2 protein content normalized to COX IV. For definitions of the study groups, see the legend for Figure 1.

dysfunction after neonatal cardioplegic arrest. Although early apoptosis-related processes are initiated (Bax translocation, mitochondrial permeabilization, and cytochrome $\mathrm{c}$ release), we have previously demonstrated that there is sparse progression to completed apoptosis $(<1 \%$ of myocytes) after 6 hours of observation in a neonatal lamb model. ${ }^{24}$ Therefore the constellation of mitochondrial alterations might represent a stalled form of apoptosis, and the clinical reality that most neonatal myocardial function returns in the early postoperative period suggests that myocyte recovery (rather than cell death) is the norm.

Proposed mechanisms for mitochondrial membrane permeabilization after ischemia-reperfusion injury include nonspecific mitochondrial swelling, rupture of the outer membrane, and MPTP opening. ${ }^{25}$ The vast majority of studies evaluating these mechanisms of mitochondrial permeabilization are in infarct models of lethal mitochondrial injury with sustained MPTP opening. In contrast, cardioplegic arrest results in a mild ischemia-reperfusion injury in which recovery of myocardial function is typical and necrosis is rare or nonexistent. ${ }^{24}$ However, the time course of restoration of mitochondrial integrity after cardioplegic arrest has not been fully studied. The present study suggests that resealing of the MPTP is nearly complete within 30 minutes after reperfusion and that mitochondrial electron transport is linked to the status of mitochondrial permeabilization.

Translocation of Bax to the mitochondria is a wellrecognized proapoptotic signal that is associated with 
mitochondrial permeabilization. Because Bax can form in vitro multimers with pore-forming capability, it has been hypothesized as a mediator of mitochondrial permeabilization in apoptotic signalling. ${ }^{26}$ Our laboratory and others have demonstrated that disruption of mitochondrial membrane integrity is associated with translocation of Bax to the mitochondrial fraction. ${ }^{2,27}$ In the present study we find evidence that Bax might be involved in mitochondrial permeabilization based on translocation of Bax to the mitochondrial fraction. In contrast, inhibition of MPTP opening with CsA administration is associated with mitochondrial preservation and diminished Bax translocation. These data are consistent with the concept that Bax translocation is downstream from MPTP opening and might participate in a feed-forward signal to enhance mitochondrial permeabilization. ${ }^{28}$ Bax mitochondrial redistribution and cytochrome c release can occur as a delayed process in isolated cell models downstream from MPTP opening. ${ }^{8}$ Bax (proapoptotic) and Bcl-2 (antiapoptotic) play opposing regulatory roles in mitochondrial permeabilization. Bax-induced mitochondrial permeability changes can be prevented by Bcl-2. ${ }^{29}$ The involvement of $\mathrm{Bcl}-2$ in the control of MPTP opening and apoptosis-related mitochondrial dysfunction was supported by our finding that inhibition of Bcl-2 by HA14-1 enhanced MPTP opening, and these changes were associated with deficits of activity in complexes I and IV that could be prevented by inhibition of Bax translocation with CsA.

In conclusion, our data suggest that cardioplegic arrest and reperfusion are associated with transient mitochondrial permeabilization of the MPTP and subsequent restoration of mitochondrial integrity within 30 minutes. Mitochondrial permeabilization is associated with ROS production, secondary Bax translocation, and dysfunctional electron transport at complexes I and IV, with a potential amplification role for Bax as a mediator of mitochondrial permeabilization. Therefore clinical strategies that are directed to minimize initial MPTP opening and apoptosis-related mitochondrial dysfunction might work in a synergistic fashion with other more conventional therapeutic modalities designed to minimize myocardial stunning and thereby improve postoperative myocardial performance.

\section{References}

1. Crow MT, Mani K, Nam YJ, Kitsis RN. The mitochondrial death pathway and cardiac myocyte apoptosis. Circ Res. 2004;95:957-70.

2. Caldarone CA, Barner EW, Wang L, Karimi M, Mascio CE, Hammel JM, et al. Apoptosis-related mitochondrial dysfunction in the early postoperative neonatal lamb heart. Ann Thorac Surg. 2004;78:948-55.

3. Oka N, Wang L, Mi W, Caldarone CA. Inhibition of mitochondrial remodeling by cyclosporine A preserves myocardial performance in a neonatal rabbit model of cardioplegic arrest. J Thorac Cardiovasc Surg. 2008;135:585-93.

4. Wernovsky G, Wypij D, Jonas RA, Mayer JE Jr, Hanley FL, Hickey PR, et al. Postoperative course and hemodynamic profile after the arterial switch operation in neonates and infants. A comparison of low-flow cardiopulmonary bypass and circulatory arrest. Circ Res. 1995;92:226-35.

5. Garlid KD, Paucek P, Yarov-Yarovoy V, Murray HN, Darbenzio RB, D'Alonzo AJ, et al. Cardioprotective effect of diazoxide and its interaction with mitochondrial ATP-sensitive $\mathrm{K}+$ channels. Possible mechanism of cardioprotection. Circ Res. 1997;81:1072-82.

6. Halestrap AP, Clarke SJ, Javadov SA. Mitochondrial permeability transition pore opening during myocardial reperfusion-a target for cardioprotection. Cardiovasc Res. 2004;61:372-85.

7. Weiss JN, Korge P, Honda HM, Ping P. Role of the mitochondrial permeability transition in myocardial disease. Circ Res. 2003;93:292-301.

8. Capano M, Crompton M. Biphasic translocation of Bax to mitochondria. Biochem J. 2002;367:169-78.

9. Pastorino JG, Tafani M, Rothman RJ, Marcinkeviciute A, Hoek JB, Farber JL. Functional consequences of the sustained or transient activation by Bax of the mitochondrial permeability transition pore. J Biol Chem. 1999;274:31734-9.

10. Kluck RM, Esposti MD, Perkins G, Renken C, Kuwana T, Bossy-Wetzel E, et al. The pro-apoptotic proteins, Bid and Bax, cause a limited permeabilization of the mitochondrial outer membrane that is enhanced by cytosol. J Cell Biol. 1999; 147:809-22.

11. Halestrap AP, Connern CP, Griffiths EJ, Kerr PM. Cyclosporin A binding to mitochondrial cyclophilin inhibits the permeability transition pore and protects hearts from ischaemia/reperfusion injury. Mol Cell Biochem. 1997;174:167-72.

12. Akao M, O'Rourke B, Kusuoka H, Teshima Y, Jones SP, Marban E. Differential actions of cardioprotective agents on the mitochondrial death pathway. Circ Res. 2003;92:195-202.

13. Wang C, Neff DA, Krolikowski JG, Weihrauch D, Bienengraeber M, Warltier DC, et al. The influence of B-cell lymphoma 2 protein, an antiapoptotic regulator of mitochondrial permeability transition, on isoflurane-induced and ischemic postconditioning in rabbits. Anesth Analg. 2006;102:1355-60.

14. Palmer JW, Tandler B, Hoppel CL. Biochemical properties of subsarcolemmal and interfibrillar mitochondria isolated from rat cardiac muscle. J Biol Chem. 1997;252:8731-9.

15. Chen Q, Camara AK, Stowe DF, Hoppel CL, Lesnefsky EJ. Modulation of electron transport protects cardiac mitochondria and decreases myocardial injury during ischemia and reperfusion. Am J Physiol Cell Physiol. 2007;292:C137-47.

16. Mootha VK, Lepage P, Miller K, Bunkenborg J, Reich M, Hjerrild M, et al. Identification of a gene causing human cytochrome $\mathrm{c}$ oxidase deficiency by integrative genomics. Proc Natl Acad Sci U S A. 2003;100:605-10.

17. William JN. A method for the simultaneous quantitative estimation of cytochrome a, b, c1 and and c in mitochondrial. Arch Biochem Biophys. 1964;107: $537-43$.

18. Javadov SA, Clarke S, Das M, Griffiths EJ, Lim KH, Halestrap AP. Ischaemic preconditioning inhibits opening of mitochondrial permeability transition pores in the reperfused rat heart. J Physiol. 2003;549:513-24.

19. Korge P, Ping P, Weiss JN. Reactive oxygen species production in energized cardiac mitochondria during hypoxia/reoxygenation: modulation by nitric oxide. Circ Res. 2008;103:873-80.

20. Griffiths EJ, Halestrap AP. Mitochondrial non-specific pores remain closed during cardiac ischaemia, but open upon reperfusion. Biochem J. 1995;307:93-8.

21. Newmeyer DD, Ferguson-Miller S. Mitochondria: releasing power for life and unleashing the machineries of death. Cell. 2003;112:481-90.

22. Dumas JF, Argaud L, Cottet-Rousselle C, Vial G, Gonzalez C, Detaille D, et al. Effect of transient and permanent permeability transition pore opening on NAD (P)H localization in intact cells. J Biol Chem. 2009;284:15117-25.

23. Petronilli V, Penzo D, Scorrano L, Bernardi P, Di Lisa F. The mitochondrial permeability transition, release of cytochrome $\mathrm{c}$ and cell death. Correlation with the duration of pore openings in situ. J Biol Chem. 2001;276:12030-4.

24. Harris MH, Thompson CB. The role of the Bcl-2 family in the regulation of outer mitochondrial membrane permeability. Cell Death Differ. 2000;7:1182-91.

25. Hammel JM, Caldarone CA, Van Natta TL, Wang L, Welke KF, Li W, et al. Myocardial apoptosis after cardioplegic arrest in the neonatal lamb. J Thorac Cardiovasc Surg. 2003;125:1268-75.

26. Antonnsson B, Montessuit S, Lauper S, Eskes R, Martinou JC. Bax oligomerization is required for channel-forming activity in liposomes and to trigger cytochrome c release from mitochondria. J Biochem. 2000;345:271-8.

27. Hirsch T, Susin SA, Marzo I, Marchetti P, Zamzami N, Kroemer G. Mitochondrial permeability transition in apoptosis and necrosis. Cell Biol Toxicol. 1998; 14:141-5.

28. De Giorgi F, Lartigue L, Bauer MK, Schubert A, Grimm S, Hanson GT, et al. The permeability transition pore signals apoptosis by directing Bax translocation and multimerization. FASEB J. 2002;16:607-9.

29. Gross A, Jockel J, Wei MC, Korsmeyer SJ. Enforced dimerization of BAX results in its translocation, mitochondrial dysfunction and apoptosis. EMBO J. 1998;17: 3878-85. 